\title{
Chapter 1 \\ Biodiversity and Health in the Face of Climate Change: Challenges, Opportunities and Evidence Gaps
}

\author{
Melissa R. Marselle, Jutta Stadler, Horst Korn, Katherine N. Irvine, \\ and Aletta Bonn
}

\begin{abstract}
Climate change presents significant challenges to human health and biodiversity. Increased numbers of extreme climate events, such as heat waves, droughts or flooding, threaten human health and well-being, both directly and indirectly, through impaired ecosystem functioning and reduced ecosystem services. In addition, the prevalence of non-communicable diseases is rising, causing ill health and accelerating costs to the health sector. Nature-based solutions, such as the provision and management of biodiversity, can facilitate human health and well-being, and mitigate the negative effects of climate change. The growing recognition of the importance of biodiversity's contribution to human health offers great potential for maximising synergies between public health, climate change adaptation and nature
\end{abstract}

\footnotetext{
M. R. Marselle $(\bowtie)$

Department of Ecosystem Services, Helmholtz Centre for Environmental Research - UFZ, Leipzig, Germany

German Centre for Integrative Biodiversity Research (iDiv) Halle-Jena-Leipzig,

Leipzig, Germany

e-mail: melissa.marselle@ufz.de

J. Stadler $\cdot$ H. Korn

Federal Agency for Nature Conservation (BfN), Isle of Vilm, Putbus, Germany

e-mail: jutta.stadler@bfn.de; horst.korn@bfn.de

K. N. Irvine

Social, Economic and Geographical Sciences Research Group, The James Hutton Institute, Aberdeen, Scotland, UK

e-mail: katherine.irvine@hutton.ac.uk
}
A. Bonn
Department of Ecosystem Services, Helmholtz Centre for Environmental Research - UFZ, Leipzig, Germany
German Centre for Integrative Biodiversity Research (iDiv) Halle-Jena-Leipzig, Leipzig, Germany
Institute of Biodiversity, Friedrich Schiller University Jena, Jena, Germany e-mail: aletta.bonn@ufz.de 
conservation. This book identifies the contribution of biodiversity to physical, mental and spiritual health and well-being in the face of climate change, and considers implications across multiple sectors.

Keywords Climate change $\cdot$ Biodiversity $\cdot$ Health $\cdot$ Nature-based solutions · Nature conservation $\cdot$ Interdisciplinarity

\section{Highlights}

- Climate change poses significant challenges to both human health and biodiversity.

- Green spaces can improve human health and well-being, and mitigate biodiversity loss.

- The inter-relationships of biodiversity to human physical, mental and spiritual aspects of health and well-being are not yet well understood.

- There is great potential for synergies between public health, climate change adaptation and biodiversity conservation.

\subsection{Background}

Climate change poses significant challenges to human health and biodiversity. Increased numbers of heat waves, droughts and flooding events due to climate change have negative consequences for both human health and biodiversity (EEA 2016, Box 1.1). The 2003 summer heat wave in Europe gave rise to 70,000 deaths, both directly through temperature stress and indirectly by affecting air quality and respiratory systems (Wolf et al. 2015). The most vulnerable people in society - the elderly, those with chronic diseases and persons of lower socio-economic status are often most affected. While susceptibility varies geographically and among groups, studies show that an increase of $1{ }^{\circ} \mathrm{C}$ in temperature above local comfort

\section{Box 1.1: Definitions of Health, Climate Change and Biodiversity}

Health is "a state of complete physical, mental and social well-being and not merely the absence of disease or infirmity" (WHO 1948).

Climate change is "any change in climate over time, resulting from natural variability or human activity" (IPCC 2007).

Biodiversity is "the variability among living organisms from all sources including, inter alia, terrestrial, marine and other aquatic ecosystems and the ecological complexes of which they are part; this includes diversity within species, between species and of ecosystems" (United Nations Convention on Biological Diversity 1992).

(For further definitions, see the Glossary, this volume). 
thresholds can be associated with an increase in mortality of up to $12 \%$ (Gabriel and Endlicher 2011). The frequency and severity of heat waves and other weatherrelated events are expected to increase in Europe with a changing climate. This will have a significant impact on biodiversity and ecosystem functioning by worsening habitat conditions (EEA 2012).

Non-communicable diseases (NCDs), for example, diabetes, cardiovascular diseases, mental disorders, cancer and chronic respiratory diseases, are a significant risk to health and well-being (WHO 2017b). NCDs are a leading cause of death globally (WHO 2017a) and account for 85\% of all deaths in Europe (WHO 2017b). These deaths are largely preventable and linked by common risk factors, such as physical inactivity, alcohol use and environmental factors (WHO 2017a). As such, population-level interventions are necessary to promote mental health and physical activity in order to prevent and control NCDs, and to reduce health-care costs. Supportive environments that facilitate healthier lifestyles and reduce exposure to stressors is one example of such an intervention. New approaches are needed to attenuate the negative effects of climate change and prevent NCDs in order to maximise opportunities for improving human health and preventing biodiversity loss.

Nature-based solutions (NBS) (Nesshöver et al. 2017), such as the management of green spaces to increase benefits for people and to mitigate stressors, might be one such approach. Work on NBS demonstrates the importance of green spaces for climate change adaptation and mitigation (Kabisch et al. 2017). Green spaces are also used as natural health clinics to promote human health and well-being (Mayer et al. 2009; Frumkin et al. 2017; Frumkin and Louv 2007), while at the same time providing habitats for a range of species (Niemela 1999; Goddard et al. 2010) and aiding conservation goals. A large body of research shows that contact with green space can improve human health and well-being, through for example reducing stress, depression and negative emotions, and improving positive emotions, mental well-being, cognitive abilities and increasing physical activity (Bowler et al. 2010b; Hartig et al. 2014; Markevych et al. 2017; Frumkin 2001; Irvine and Warber 2002), suggesting that nature can promote public health and prevent NCDs. Moreover, evidence suggests that positive experiences in nature contribute to feelings of connection to nature (Mayer et al. 2009), which could also result in greater acceptance of nature conservation activities (Prévot et al. 2018), and thereby protection of our foundation of life on earth (Geng et al. 2015; Zelenski et al. 2015; Capaldi et al. 2015).

In this context, there is growing recognition of the contribution of biodiversity to climate change adaptation and human health. Street trees and green space in cities can contribute to climate change adaptation by reducing the impact of high temperatures, poor air quality and high water flows (Bowler et al. 2010a, Gill et al. 2007). Biodiversity underpins ecosystem services that are essential for human health and well-being (Cardinale et al. 2012). Ecosystem services provided by biodiversity include the provision of food, timber and medicines as well as climate and water regulation, and cultural services such as the provision of opportunities for recreation (WHO \& CBD 2015). Yet biodiversity loss can negatively influence physical health 
through loss of these vital services, diminished options for medicines and increased transmission of infectious diseases (WHO \& CBD 2015; Sandifer et al. 2015; Hough 2014). Unsurprisingly then, biodiversity has been shown to be positively associated with good physical health (Hough 2014; Lovell et al. 2014). Less understood, however, are the impacts of biodiversity on other aspects of human health and well-being. Whilst a fast-growing field of research is investigating the influence of biodiversity on mental health and well-being (Aerts et al. 2018; Lovell et al. 2014; Dallimer et al. 2012; Fuller et al. 2007; Wheeler et al. 2015; Cox et al. 2017; Marselle et al. 2015, 2016; Carrus et al. 2015; Cracknell et al. 2016, 2017; Johansson et al. 2014), work is still progressing in this area, and evidence gaps remain. For example, the mechanistic pathways through which biodiversity influences mental health and well-being is undeveloped. Several models consider the pathways through which nature might influence various dimensions of health and well-being (Hartig et al. 2014; Markevych et al. 2017), yet it is unknown whether these same mechanistic pathways would hold for biodiversity and health and well-being relationships. In this book, we aim to synthesise existing studies and further develop the research agenda.

Increasingly, the importance of biodiversity for human health and well-being is being recognised by international governments and organizations (WHO \& CBD 2015, CBD 2017a, ten Brick et al. 2016). The linkage between biodiversity and human health is at the heart of several high-level strategic decisions being taken at a national and international scale. The Convention of Biological Diversity (CBD) and the World Health Organization (WHO) are collaborating to promote the interlinkages between biodiversity and human health sectors as secured in the Conference of the Parties (COP) 12 Decision XII/21 and joint publications (WHO \& CBD 2015, CBD 2017a, b, c). The Health 2020 policy framework of the WHO European Region identifies the importance of environmental conditions as health determinants, and has recently published a review of the evidence of urban green space for health (WHO 2017c). The United Nations 2030 Agenda on Sustainable Development has dedicated Sustainable Development Goals (SDGs) both for health and biodiversity, and current activities under the CBD aim to closely align health and biodiversity issues. The relevance of biodiversity to physical and mental health is also reflected in levels of EU research activity, the quantity of public and private expenditure, and the number of high-profile government initiatives on biodiversity and health (EKLIPSE 2017). High-profile international initiatives and research on biodiversity and health also highlight this burgeoning area (e.g. United Nations Environment Programme (UNEP), the International Association for Ecology and Health (Eco Health), and One Health).

Awareness of the significant potential for synergies between improvement of human health and adaptation to climate change with conservation of biodiversity is also increasing in applied resource management, urban planning, landscape architecture and protected areas management. In practice, there is growing interest in the use of green space in general, and biodiversity in particular, for physical, mental 
and/or spiritual health and well-being. For example, city urban planning projects encourage physical exercise through green infrastructure as a measure to improve human health (Marselle et al. 2013), while also contributing to climate change adaptation as well as to nature conservation. Use of green spaces for health has been advocated inter alia by the New Zealand Ministry of Health's 'Green Prescriptions' programme, ${ }^{1}$ the USA National Park Service's 'Parks and Trails Prescription Partnerships' programme, ${ }^{2}$ as well as by the German Government's 'Soziale Stadt' ${ }^{3}$ and 'Grün in der Stadt' ${ }^{4}$ initiatives, the German Federal Agency for Nature Conservation's 'Urban Biodiversity's theme, the 'Outdoors for All' programme by Natural England ${ }^{6}$ and Scottish Natural Heritage's 'Our Natural Health Service' initiative. $^{7}$ These co-benefits can only be achieved, however, through joined-up, collaborative, cross-sectoral and transdisciplinary working, and in this book we demonstrate with case studies good practice examples.

Awareness of the impacts of climate change and biodiversity on human health is growing. With this book, we hope to catalyse the discussion about the integral links between climate change, biodiversity and human health. Specifically, this book not only identifies the contribution of biodiversity to physical health, but also to mental and spiritual health and well-being in the face of climate change. The implications of the biodiversity-health relationship for public health, nature conservation, proenvironmental behaviour, protected areas and landscape architecture and design are detailed. The book compiles current policy and practice integrating biodiversity, human health and climate change adaptation at both national and international levels.

\subsection{Scope of the Book}

Integrating biodiversity, human health and climate change requires new approaches and transdisciplinary working. One of the challenges facing research, policy and practice on biodiversity and health is that the science has not fully joined together the different disciplines of biodiversity, ecology, public health, psychology, natural resource management, urban planning and landscape architecture to provide a

\footnotetext{
${ }^{1}$ http://www.health.govt.nz/our-work/preventative-health-wellness/physical-activity/greenprescriptions

${ }^{2}$ https://www.nps.gov/public_health/hp/hphp/partners_ptp.htm

${ }^{3}$ https://www.bmi.bund.de/DE/themen/bauen-wohnen/stadt-wohnen/staedtebau/soziale-stadt/ soziale-stadt-node.html;jsessionid=9F4F2DB35101A11DD1530AE7BA605ABB.1_cid287

${ }^{4} \mathrm{https}: / /$ www.gruen-in-der-stadt.de/

${ }^{5}$ https://www.bfn.de/themen/planung/siedlungsbereich.html

${ }^{6} \mathrm{http} / / / \mathrm{www}$.gov.uk/government/publications/outdoors-for-all-fair-access-to-a-goodquality-natural-environment

${ }^{7}$ https://www.nature.scot/professional-advice/contributing-healthier-scotland/our-naturalhealth-service
} 
cohesive evidence base for action. Whilst studies investigate the impacts of climate change on biodiversity and on human health, at present there is limited research detailing the inter-relationships of all three topics together. In applied resource management, nature conservation needs to better link to the health sector and vice versa (WHO \& CBD 2015). The health sector, whilst it has begun to incorporate the health benefits of climate change adaptation (Watts et al. 2015), has yet to fully appreciate the influence of biodiversity. Likewise, the nature conservation community needs to harness synergies with public health and climate change adaptation. The scope of this book is to align these three areas of research and to link to application in policy and practice.

This book brings together experts from transdisciplinary fields in science, policy and practice to provide an overview of the current state of knowledge on biodiversity and health relationships in the face of climate change. As such, this book provides a synthesis of the current state of the knowledge drawing from ecology, geography, environmental psychology, public health, medical science and urban planning. Moreover, experts discuss the implications that the health benefits of biodiversity have for public health, nature conservation and environmental sustainability. The book also captures in-depth, practical expertise and experience from protected area managers and landscape architects. National and international policy and practice activities regarding biodiversity, health and climate change interrelationships from health and nature conservation agencies are also detailed.

The scope of this book is on biodiversity's contribution to physical, mental and spiritual health and well-being in the face of climate change. This makes it unique compared to other books that focus on the effect of biodiversity on human physical health (Morand and Lajaunie 2017, Chivian and Bernstein 2008, Grifo and Rosenthal 1997), the contribution of green spaces to physical and mental health (Nilsson et al. 2011, Pearlmutter et al. 2017) or social-environmental equity perspectives on nature-health relationships (Kopnina and Keune 2010). In addition, the recognition of climate change as an important factor influencing biodiversity as well as health takes up new aspects of the current debate, encouraging new thinking alongside joined-up collaboration and transdisciplinary working. Consequently, some topics of biodiversity and health, such as medicine, food and nutrition, are not covered in this book, as they have already been extensively covered elsewhere (see Morand and Lajaunie 2017, Chivian and Bernstein 2008, Grifo and Rosenthal 1997). As the book focuses on biodiversity in the natural environment, consideration of the human microbiome is also not included here.

Many of the topics discussed in this book were intensely discussed at the European conference 'Biodiversity and Health in the Face of Climate Change' that took place in Bonn, Germany, from 27-29 June 2017 (Marselle et al. 2018). The conference was organised by the German Federal Agency for Nature Conservation (BfN), the Helmholtz Centre for Environmental Research-UFZ, the German Centre for Integrative Biodiversity Research (iDiv) Halle-Jena-Leipzig, the Network of European Nature Conservation Agencies (ENCA), and co-sponsored by the WHO Regional Office for Europe. We hope this book contributes to an increased under- 
standing of how green spaces and biodiversity can contribute to human health in a changing climate.

\subsection{Structure and Contents of the Book}

This book is structured in four main parts. The first two parts highlight the important contribution of green spaces and biodiversity to physical health on the one hand, and mental and spiritual health and well-being on the other hand, in a changing climate. Here we also touch on theoretical and methodological considerations. Part III discusses the implications of biodiversity on human health and well-being for specific sectors and describes the current policy and practice perspective. The final part addresses the co-benefits and the implementation challenges associated with the planning and management of urban green spaces for both biodiversity and human health.

1. Part I: Biodiversity and physical health

2. Part II: Biodiversity, mental health and spiritual well-being

3. Part III: Implications of the biodiversity and health relationship

4. Part IV: Planning and managing urban green spaces for biodiversity and health in a changing climate

The various chapters provide up-to-date scientific background information, address policy-related issues, lay out pressing urban planning and biological conservation management questions and identify knowledge gaps. Different chapters provide specific examples and applications of the use of urban green spaces for human health, nature conservation and climate change adaptation with case studies, mainly from Europe and North America. Here we provide a summative overview of each of the book's four parts.

\subsubsection{Part I: Biodiversity and Physical Health}

The first part considers the impacts that biodiversity has on physical health. The focus is on non-communicable diseases that can be caused or prevented by exposure to green space and biodiversity. The impacts of climate change on biodiversityhealth relationships are additionally highlighted in the first three chapters.

In the first chapter, Sarah Lindley and co-authors provide a general overview of the interlinkages between biodiversity, health and climate change. They highlight the role that climate change has on human health and the adaptation role that NBS can play; this is illustrated with a case study from Manchester, England. Athanasios Damialis and co-authors discuss the impact of climate change on biodiversity and human health through the expanding geographical spread of allergies and allergenic pollen. Further negative effects of biodiversity on human health by vector-borne 
diseases, that may become more prevalent due to a changing climate, are reviewed by Ruth Müller and co-authors. The authors highlight how climate change shapes the distribution and abundance of disease vectors, and the role biodiversity can play in this relationship. The health effects of green space for different socio-economic and socio-demographic population groups is addressed by Nadja Kabisch. Conclusions are drawn about how to design green spaces that are beneficial for the health and well-being of all population groups to protect the most vulnerable in society. Complementing this chapter, Payam Dadvand and co-authors show how urban green spaces can affect the health and development of children living in urban environments. In their review, the authors identify how green spaces influence prenatal development and pregnancy outcomes, children's brain development as well as effects on respiratory conditions and physical activity.

\subsubsection{Part II: Biodiversity, Mental Health and Spiritual Well-Being}

Chapters in the second part of the book discuss the evidence of the impact of biodiversity on mental health and spiritual well-being. The first two chapters touch on theoretical and methodological issues for biodiversity and mental health and wellbeing relationships. The latter chapters review the evidence on the influence biodiversity has on mental health and spiritual well-being.

To set the scene, Melissa Marselle provides an overview of the theoretical frameworks that provide a perspective into the ways that biodiversity can influence mental well-being. Complementing this chapter, Sjerp de Vries and Robbert Snep highlight conceptual issues associated with the design of studies when investigating the effect of biodiversity on mental health, drawing out key methodological issues to be considered in future research on biodiversity-mental health relationships. The next chapter by Melissa Marselle and co-authors provides a comprehensive review of the scientific literature on how biodiversity can affect mental health and wellbeing based on a synthesis of 24 studies. Katherine Irvine and colleagues examine evidence of the inter-relationship between biodiversity and spiritual well-being.

\subsubsection{Part III: Implications of the Biodiversity and Health Relationship}

The third part of this book focuses on the policy and practice implications of biodiversity and health relationships. In particular, the implications of this relationship from the perspective of public health, nature conservation and efforts to promote pro-environmental behaviour are highlighted. The latter chapters review the national 
and international policy and practice support for biodiversity, climate change, and human health.

Penny Cook and co-authors provide a comprehensive overview of the scientific literature on the linkages between public health, climate change and biodiversity. The authors demonstrate how access to, and use of, urban green spaces can reduce social inequalities in health, a key goal of modern public health policies and programmes. Reflecting on the health and well-being benefits of nature, Zoe Davies and colleagues discuss the management options to ensure that both biodiversity conservation and people's health are considered. The authors argue that the evidence on biodiversity-health relationships suggests that green spaces should be managed for both people and biodiversity conservation. As the consequences of climate change and biodiversity loss will require humans to change their behaviour to consume far fewer resources in a resource finite world, Raymond De Young discusses how to initiate long-term behaviour change. The author argues for a "capacities-first approach" to support people to become "behavioural entrepreneurs" and self-initiate behaviour change. To assess how health agendas are embedded in biodiversity policies and vice versa, Horst Korn and co-authors review the international policy agendas with the potential to foster linkages between biodiversity conservation and human health, and identify alignments between sectors and avenues for implementation. Reflecting on institutional aspects and challenges of integrating nature and health, Hans Keune and co-authors highlight the need for increased and improved collaboration between the health and nature sectors, as well as science, policy and practice. The chapter presents several international/European examples of nature and health network initiatives as well as various national activities in Europe alongside summarising successes and challenges of each initiative.

\subsubsection{Part IV: Planning and Managing Urban Green Spaces for Biodiversity and Health in a Changing Climate}

The last part focuses on planning and managing green spaces in and around cities for nature conservation, health and climate change adaptation. In particular, this part discusses how managers of protected areas and urban green space can work with other sectors to maximise the benefits of these places, and how landscape planners can design urban environments that benefit both people and nature.

Kathy MacKinnon and colleagues provide a scene-setting chapter in which they highlight the benefits and services that NBS and protected areas provide for biodiversity, health and climate change adaptation, inter alia in the context of the SDGs. The authors discuss the need for increased and improved collaboration between sectors and stakeholders to foster the use of NBS and protected areas for these multiple benefits. Complementing this chapter, Ruth Hunter and co-authors review the effectiveness of urban green space interventions for improving health and biodiversity and provide recommendations for research, policy and practice 
regarding the design of these types of interventions. Thomas Elmqvist and coauthors propose applying systems thinking to foster sustainable urban development and resilience. They discuss Knowledge-Action-Systems for urban health, in which knowledge of complex urban system functions and interactions with climate change, and NBS for economic, environmental and social dimensions of urban development, are interlinked by constant feedback loops. The last chapter in this part by Stefan Heiland and colleagues refers to the opportunities for integrating human health into landscape planning projects in order to cope with climate change and societal change. The authors discuss planning policy opportunities for incorporating health issues in Germany and the UK, and provide examples of health-promoting landscape design.

The book is complemented with a conclusion chapter which summarises the main challenges for research, policy and practice described in the chapters, highlights opportunities for future developments, and presents recommendations for tackling the inter-related issues of biodiversity, health and climate change.

We hope this book provides important pointers to the flourishing debate on the importance of biodiversity to human health in this current time of climate change, and illustrates good practice with demonstration case studies. Ultimately, we hope this book can fuel further advances in science, policy and practice. Many of the themes have applications beyond urban systems as they focus on solutions for public health, biodiversity conservation and climate adaptation in a changing world.

Acknowledgements This work was supported by the German Federal Agency for Nature Conservation (BfN) with funds of the German Federal Ministry for the Environment, Nature Conservation, and Nuclear Safety (BMU) through the research project "Conferences on Climate Change and Biodiversity" (BIOCLIM, project duration from 2014 to 2017, funding code: 351480 020A). Dr. Irvine's involvement was funded by the Rural \& Environment Science \& Analytical Services Division of the Scottish Government.

\section{References}

Aerts R, Honnay O, Van Nieuwenhuyse A (2018) Biodiversity and human health: mechanisms and evidence of the positive health effects of diversity in nature and green spaces. Br Med Bull 127(1):5-22

Bowler DE, Buyung-Ali L, Knight TM, Pullin AS (2010a) Urban greening to cool towns and cities: a systematic review of the empirical evidence. Landsc Urban Plan 97:147-155. https://doi. org/10.1016/j.landurbplan.2010.05.006

Bowler DE, Buyung-Ali L, Knight T, Pullin AS (2010b) A systematic review of evidence for the added benefits to health of exposure to natural environments. BMC Public Health 10:456. https://doi.org/10.1186/1471-2458-10-456

Capaldi CA, Passmore H, Nisbet EK, Zelenski JM, Dopko RL (2015) Flourishing in nature: a review of the benefits of connecting with nature and its application as a wellbeing intervention. Int J Wellbeing 5(4):1-16. https://doi.org/10.5502/ijw.v5i4.449

Cardinale BJ, Duffy JE, Gonzalez A et al (2012) Biodiversity loss and its impact on humanity. Nature 486:59-67. https://doi.org/10.1038/nature11148

Carrus G, Scopelliti M, Lafortezza R et al (2015) Go greener, feel better? The positive effects of biodiversity on the well-being of individuals visiting urban and peri-urban green areas. Landsc Urban Plann 134:221-228 
CBD (2017a) Biodiversity and human health. Secretariat of the Convention on Biological Diversity, Montreal, Canada. https://www.cbd.int/doc/c/72d6/b5bb/9244e977048688ec45735d2c/sbstta21-04-en.pdf. Accessed 30 Jan 2018

CBD (2017b) Recommendation adopted by the subsidiary body on scientific, technical and technological advice. XXI/3. Health and biodiversity. Secretariat of the Convention on Biological Diversity, Montreal, Canada. https://www.cbd.int/doc/recommendations/sbstta-21/sbstta-21rec-03-en.pdf. Accessed 12 Jan 2018

CBD (2017c) Workshop on biodiversity and health for the European Region. Secretariat of the Convention on Biological Diversity, Montreal, Canada. https://www.cbd.int/health/european/ default.shtml. Accessed 12 Jan 2018

Chivian E, Bernstein A (eds) (2008) Sustaining life: how our health depends on biodiversity. Oxford University Press, Oxford

Cox DTC, Shanahan DF, Hudson HL et al (2017) Doses of neighborhood nature: the benefits for mental health of living with nature. Bioscience 67:147-155. https://doi.org/10.1093/biosci/ biw173

Cracknell D, White MP, Pahl S, Nichols WJ, Depledge MH (2016) Marine biota and psychological well-being: a preliminary examination of dose-response effects in an aquarium setting. Environ Behav 48(10):1242-1269. https://doi.org/10.1177/0013916515597512

Cracknell D, White MP, Pahl S, Depledge MH (2017) A preliminary investigation into the restorative potential of public aquaria exhibits: a UK student-based study. Landsc Res 42(1):18-32. https://doi.org/10.1080/01426397.2016.1243236

Dallimer M, Irvine KN, Skinner AMJ et al (2012) Biodiversity and the feel-good factor: understand associations between self-reports human well-being and species richness. Bioscience 62(1):47-55

EEA (2012) Climate change, impacts and vulnerability in Europe 2012. An indicator-based report. European Environment Agency, Copenhagen, Denmark. https://www.eea.europa.eu/ publications/climate-impacts-and-vulnerability-2012

EEA (2016) Extreme temperatures and health. European Environment Agency, Copenhagen, Denmark. https://www.eea.europa.eu/data-and-maps/indicators/heat-and-health-2/assessment

EKLIPSE (2017) Types and components of natural or man-made urban and suburban green and blue spaces affecting human mental health and mental well-being. Available: http://www. eklipse-mechanism.eu/documents/32503/0/Final_DoW_Health_08092017.pdf/d5e269a2da6b-4809-9458-fd9747ca383c. Accessed 15 Jan 2018

Frumkin H (2001) Beyond toxicity: human health and the natural environment. Am J Prev Med 20(3):234-240

Frumkin H, Louv R (2007) The powerful link between conserving land and preserving health. Land Trust Alliance, Washington, DC

Frumkin H, Bratman GN, Breslow SJ et al (2017) Nature contact and human health: a research agenda. Environ Health Perspect 125(7):075001. https://doi.org/10.1289/EHP1663

Fuller RA, Irvine KN, Devine-Wright P, Warren PH, Gaston KJ (2007) Psychological benefits of greenspace increase with biodiversity. Biol Lett 3:390-394

Gabriel KM, Endlicher WR (2011) Urban and rural mortality rates during heat waves in Berlin and Brandenburg, Germany. Environ Pollut 159:2044-2050

Geng L, Xu J, Ye L, Zhou W, Zhou K (2015) Connection with nature and environmental behaviors. PLoS One 10(5):e0127247. https://doi.org/10.1371/journal.pone.0127247

Gill SE, Handley JF, Ennos AR, Pauleit S (2007) Adapting cities for climate change: the role of the green infrastructure. Built Environ 33:155-133

Goddard M, Dougill AJ, Benton TG (2010) Scaling up from gardens: biodiversity conservation in urban environments. Trends Ecol Evol 25:90-98. https://doi.org/10.1016/j.tree.2009.07.016

Grifo F, Rosenthal J (eds) (1997) Biodiversity and human health. Island Press, Washington, DC

Hartig T, Mitchell R, de Vries S, Frumkin H (2014) Nature and health. Annu Rev Public Health 35:207-228. https://doi.org/10.1146/annurev-publhealth-032013-182443

Hough R (2014) Biodiversity and human health: evidence for causality? Biodivers Conserv 23:267-288 
IPCC (2007) Climate change 2007: the physical science basis. In: Solomon S, Qin D, Manning M, Chen Z, Marquis M, Averyt KB, Tignor M, Miller HL (eds) Contribution of working group I to the fourth assessment report of the intergovernmental panel on climate change. Cambridge University Press, Cambridge. http://www.ipcc.ch/publications_and_data/ar4/wg1/en/contents. html

Irvine KN, Warber SL (2002) Greening healthcare: practicing as if the natural environment really mattered. Altern Ther Health Med 8(5):76-83

Johansson M, Gyllin M, Witzell J, Küller M (2014) Does biological quality matter? Direct and reflected appraisal of biodiversity in temperate deciduous broad-leaf forest. Urban For Urban Green 13:28-37

Kabisch N, Stadler J, Korn H, Bonn A (eds) (2017) Nature-based solutions to climate change in urban areas - Linkages between science, policy and practice, Theory and Practice of Urban Sustainability Transitions. Springer International Publishing, Cham

Kopnina H, Keune H (2010) Health and environment: social science perspectives. Nova Science Publishers, New York

Lovell R, Wheeler BW, Higgins SL, Irvine KN, Depledge MH (2014) A systematic review of the health and wellbeing benefits of biodiverse environments. J Toxicol Environ Health B Crit Rev 17(1):1-20. https://doi.org/10.1080/10937404.2013.856361

Markevych I, Schoierer J, Hartig T et al (2017) Exploring pathways linking greenspace to health: theoretical and methodological guidance. Environ Res 158:301-317. https://doi.org/10.1016/j. envres.2017.06.028

Marselle MR, Irvine KN, Warber SL (2013) Walking for well-being: are group walks in certain types of natural environments better for well-being than group walks in urban environments? Int J Environ Res Public Health 10:5603-5628

Marselle MR, Irvine KN, Lorenzo-Arribas A, Warber SL (2015) Moving beyond green: exploring the relationship of environment type and indicators of perceived environmental quality on emotional well-being following group walks. Int J Environ Res Public Health 12(1):106. https:// doi.org/10.3390/ijerph120100106

Marselle MR, Irvine KN, Lorenzo-Arribas A, Warber SL (2016) Does perceived restorativeness mediate the effects of perceived biodiversity and perceived naturalness on emotional wellbeing following group walks in nature? J Environ Psychol 46:217-232

Marselle MR, Stadler J, Korn H, Bonn A (eds) (2018) Proceedings of the European Conference "Biodiversity and Health in the Face of Climate Change - Challenges, Opportunities and Evidence Gaps". BfN-Skripten 509. Federal Agency for Nature Conservation, Bonn, Germany. https://www.bfn.de/fileadmin/BfN/service/Dokumente/skripten/Skript509.pdf

Mayer FS, Frantz CM, Bruehlman-Senecal E, Dolliver K (2009) Why is nature beneficial? The role of connectedness to Nature. Environ Behav 41(5):607

Morand S, Lajaunie C (eds) (2017) Biodiversity and health: linking life, ecosystems and societies. Elsevier, Oxford

Nesshöver C, Assmuth T, Irvine KN et al (2017) The science, policy and practice of nature-based solutions: an interdisciplinary perspective. Sci Total Environ 579:1215-1227

Niemela J (1999) Ecology and urban planning. Biodivers Conserv 8:119-131

Nilsson K, Sangster M, Gallis C et al (eds) (2011) Forest, trees and human health. Springer, Dordrecht

Pearlmutter D, Calfapietra C, Samson R et al (eds) (2017) The urban forest: cultivating green infrastructure for people and the environment. Springer, Cham

Prévot A-C, Cheval H, Raymond R, Cosquer A (2018) Routine experiences of nature in cities can increase personal commitment toward biodiversity conservation. Biol Conserv 226:1-8. https://doi.org/10.1016/j.biocon.2018.07.008

Sandifer PA, Sutton-Grier AE, Ward BP (2015) Exploring connections among nature, biodiversity, ecosystem services, and human health and well-being: opportunities to enhance health and biodiversity conservation. Ecosyst Serv 12:1-15. https://doi.org/10.1016/j.ecoser.2014.12.007

ten Brick P, Mutafogla K, Schweitzer J et al. (2016) The health and social benefits of nature and biodiversity protection. Institute for European Environmental Policy (IEEP), London/Brussels. https://ieep.eu/publications/new-study-on-the-health-and-social-benefits-of-biodiversity-andnature-protection. Accessed 30 July 2018 
United Nations Convention on Biological Diversity (1992) Convention on Biological Diversity. https://www.cbd.int/doc/legal/cbd-en.pdf. Accessed 12 July 2018

Watts N, Adger WN, Agnolucci P et al (2015) Health and climate change: policy responses to protect public health. Lancet 386:1861-1914

Wheeler BW, Lovell R, Higgins SL et al (2015) Beyond greenspace: an ecological study of population general health and indicators of natural environment type and quality. Int J Health Geogr 14(1):17. https://doi.org/10.1186/s12942-015-0009-5

WHO (2017a) Fact sheets on sustainable development goals: health targets for noncommunicable diseases. World Health Organization Regional Office for Europe, Copenhagen, Denmark. http://www.euro.who.int/_data/assets/pdf_file/0007/350278/Fact-sheet-SDG-NCDFINAL-25-10-17.pdf?ua=1. Accessed 30 July 2018

WHO (2017b) Noncommunicable diseases. World Health Organization regional Office for Europe, Copenhagen, Denmark. http://www.euro.who.int/en/health-topics/noncommunicablediseases. Accessed 13 July 2018

WHO (2017c) Urban green space interventions and health: a review of impacts and effectiveness. World Health Organization regional Office for Europe, Copenhagen, Denmark. http:// www.euro.who.int/_data/assets/pdf_file/0010/337690/FULL-REPORT-for-LLP.pdf?ua=1. Accessed 30 July 2018

WHO \& CBD (2015) Connecting global priorities: biodiversity and human health. A state of the knowledge review. World Health Organization \& Secretariat of the Convention on Biological Diversity. http://www.who.int/globalchange/publications/biodiversity-human-health/en/. Accessed 30 July 2018

Wolf T, Lyne K, Martinez GS, Kendrovski V (2015) The health effects of climate change in the WHO European region. Climate 3:901-936

World Health Organization (1948) Constitution of WHO: principles. http://www.who.int/about/ mission/en/

Zelenski JM, Dopko RL, Capaldi CA (2015) Cooperation is in our nature: nature exposure may promote cooperative and environmentally sustainable behavior. J Environ Psychol 42:24-31

Open Access This chapter is licensed under the terms of the Creative Commons Attribution 4.0 International License (http://creativecommons.org/licenses/by/4.0/), which permits use, sharing, adaptation, distribution and reproduction in any medium or format, as long as you give appropriate credit to the original author(s) and the source, provide a link to the Creative Commons license and indicate if changes were made.

The images or other third party material in this chapter are included in the chapter's Creative Commons license, unless indicated otherwise in a credit line to the material. If material is not included in the chapter's Creative Commons license and your intended use is not permitted by statutory regulation or exceeds the permitted use, you will need to obtain permission directly from the copyright holder.

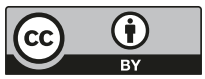

